OPEN ACCESS

Edited by:

Yixin Zhang,

Soochow University, China

Reviewed by:

Yu Liu,

Northwest A\&F University, China

Peng Luo,

Chengdu Institute of Biology, Chinese Academy of Sciences (CAS), China

*Correspondence: Yangong Du

ygdu@nwipb.cas.cn

Specialty section:

This article was submitted to

Conservation and Restoration Ecology,

a section of the journal

Frontiers in Ecology and Evolution

Received: 23 March 2021

Accepted: 31 October 2021

Published: 16 December 2021

Citation:

Wang Y, Pei W, Cao G, Guo X, Zhou H and Du Y (2021) Moderate

Grazing Increases Water Use Efficiency for Environmental Health in Alpine Meadows of the Tibetan Plateau. Front. Ecol. Evol. 9:684321. doi: 10.3389/fevo.2021.684321

\section{Moderate Grazing Increases Water Use Efficiency for Environmental Health in Alpine Meadows of the Tibetan Plateau}

\author{
Yunying Wang 1,2, Weiwei Pei ${ }^{1,2}$, Guangmin Cao ${ }^{1}$, Xiaowei Guo', Huakun Zhou ${ }^{1}$ and \\ Yangong Dut,3*
}

${ }^{1}$ Qinghai Provincial Key Laboratory of Restoration Ecology for Cold Regions, Northwest Institute of Plateau Biology, Chinese Academy of Sciences, Xining, China, ${ }^{2}$ College of Resource and Environment, University of Chinese Academy of Sciences,

Beijing, China, ${ }^{3}$ College of Geology, Qinghai Normal University, Xining, China

Water use efficiency is an important indicator of drought tolerance in plants. The response of the water use efficiency to different grazing intensities and adaptive mechanisms in alpine meadows remains unclear. To understand the changes in water use in alpine meadow ecosystems under different grazing gradients, grazing systems have to be optimized, and severely receding grasslands should be effectively restored. This study analyzed the response of water use efficiency of plant dominant species, coexisting species, and functional group-level plants to grazing intensity using the $\delta^{13} \mathrm{C}$ index in an alpine meadow. We found that grazing increased the leaf carbon isotope composition in plants $\left(\delta^{13} \mathrm{C}\right)$ of Gramineae by $3.37 \%$ and grazing at a moderate level significantly increased it by $4.84 \%(P<0.05)$. In addition, an increase in $\delta^{13} \mathrm{C}$ was observed in the functional groups of Cyperaceae (3.45\%), Leguminosae $(0.81 \%)$, and Forb (1.40\%). However, some dominant species and coexisting species showed the highest $\delta^{13} \mathrm{C}$ values under moderate grazing. These results indicate that moderate grazing may significantly improve the water use efficiency of species in alpine meadows. The path analysis showed that water use efficiency was negatively correlated with evapotranspiration $(P<0.05)$, soil water content, soil organic carbon, and soil bulk density. Nevertheless, there was a positive correlation between water use efficiency and the available nitrogen. This study concluded that moderate grazing could improve the efficiency of grassland water use to a certain extent. Additionally, soil evapotranspiration was the main driving factor affecting the water use efficiency of alpine meadows.

Keywords: available nitrogen, evapotranspiration, environmental factors, grazing activity, $\delta^{13} \mathrm{C}$

\section{INTRODUCTION}

Leaf carbon isotope composition in plants $\left(\delta^{13} \mathrm{C}\right)$ integrates photosynthetic activities during the synthesis of the plant leaf tissue, reflecting the relative relationship between plant water loss and carbon harvest (Shen et al., 2019). This indirectly indicates the long-term water use efficiency (WUE; Farquhar et al., 1982; Stewart et al., 1995; Liu et al., 2016). Recent studies have shown that 
the $\delta^{13} \mathrm{C}$ value of plant leaves has a positive correlation with WUE. Larger $\delta^{13} \mathrm{C}$ values indicate higher plant WUE (Farquhar et al., 1982; Su et al., 2005; Shen et al., 2017).

More than $60 \%$ of alpine meadows are often overgrazed. Grazing is the leading cause of degradation of alpine meadows (Cao et al., 2018). Previous studies focused on the impact of grazing intensity on grassland multifunctions (Du et al., 2019; Shen et al., 2019; Zhang et al., 2019). While grazing activities play a role in balancing and stabilizing the plant community (Wang, 2018), they also decrease the biomass and diversity of grassland ecosystems (Xu et al., 2015; Lin et al., 2017), soil water content (Lin et al., 2011; Zhang et al., 2019), and evapotranspiration processes (He et al., 2017; Shu et al., 2019; Zhang et al., 2019). Stable carbon isotope technology is fast and accurate owing to its labeling, integration, and indication functions (Jiang et al., 2020). For example, the analysis of monthly and annual changes in WUE in desert plants using the $\delta^{13} \mathrm{C}$ stable isotope technology has found that plants have long-term WUE (Su et al., 2005). Grazing has a significant impact on stable isotope indicators in plants (Chen, 2003). Studies on grazing pastures in Guinea, Brazil, Tanzania, and plant WUE showed an increasing trend under moderate grazing (Cavalcante et al., 2016; Wang et al., 2016). The $\delta^{13} \mathrm{C}$ of Stipa breviflora plants showed a downward trend with an increasing grazing activity (Wang et al., 2016). The WUE of typical plants showed a downward trend under grazing conditions, but that of soil showed an upward trend in the desert steppe of Inner Mongolia (Zhu et al., 2016).

The $\delta^{13} \mathrm{C}$ value is affected by environmental factors, such as evapotranspiration, soil water content, soil organic carbon, and soil bulk density, which affect plant WUE. A negative correlation exists between the changes in precipitation and WUE (Zhang et al., 2003). With a $100 \mathrm{~mm}$ increase in rainfall, the $\delta^{13} \mathrm{C}$ value of the plant is negative $(0.33 \%$ ) (Stewart et al., 1995). The soil water content has a weak negative correlation with WUE (Wu et al., 2019). The WUE of the Haibei alpine meadow in Qinghai had a positive correlation with changes in evapotranspiration (Shi et al., 2020). Zhu et al. (2020) studied the correlation between the $\delta^{13} \mathrm{C}$ value and soil organic carbon under different grazing regimes in the Xilamuren desert steppe in central and western Inner Mongolia and found a negative correlation between them. The soil organic carbon content in Panyang Lake was different from that in $\delta^{13} \mathrm{C}$, and the relationship between the two was also found to be negative (Wang et al., 2016).

Grazing is the primary mode of grassland ecosystem utilization. Many studies have been conducted on the efficiency of plant water use in grassland ecosystems, with current studies focusing on the community level. However, only few studies have explored the dynamic characteristics of alpine meadow WUE in response to grazing in terms of dominant species, coexisting species, and functional group levels. Some studies based on the $\delta^{13} \mathrm{C}$ stable isotope technology have found that the best time for sampling to characterize the long-term plant WUE should be late August or early September (Su et al., 2005). To better clarify the change characteristics of water use efficiency in alpine meadows, the main objectives of this study are (1) to determine the characteristics of changes in WUE of dominant species, coexisting species, and functional group species in alpine meadows under different grazing intensity treatments, (2) to quantitatively evaluate the effects of environmental factors on the changes in WUE of alpine meadows regulatory mechanism, and (3) to provide a scientific basis for the restoration of degraded grasslands and the sustainable use of the ecosystem.

Therefore, we sampled plant leaves in late August during the growing season. Under the three treatments of enclosure, moderate, and heavy grazing, our experiment proposed the following hypotheses: (1) compared with enclosure treatment, grazing will improve the WUE and the environmental health of the grassland and (2) total nitrogen and water contents of soil could drive WUE changes in alpine meadows.

\section{MATERIALS AND METHODS}

\section{Site Description}

The study was carried out in Qinghai Haibei alpine grassland ecosystem national observation and research station (Haibei Station, $\left.37^{\circ} 39.876^{\prime} \mathrm{N}, 101^{\circ} 10.748^{\prime} \mathrm{E}, 3227.6 \mathrm{~m}\right)$. The plant growing season is not disturbed by grazing activity because the grazing period ranged from the beginning of October to the end of April of the following year. It belongs to a typical plateau continental climate. The annual average precipitation and temperature are $560 \mathrm{~mm}$ and $-1.7^{\circ} \mathrm{C}$, respectively. During the growing season, the precipitation from May to September accounts for about $80 \%$ of the total annual precipitation. The plant-growing season has rain and heat simultaneously, and the soil type is alpine meadow soil.

The native vegetation of the alpine meadow is the cold mesophytic, wet mesophytic, or dry mesophytic perennial Kobresia, which is a constructive vegetation type. The community structure is relatively complex, and the species composition is rich. There are about 30 species per $\mathrm{m}^{2}$. The dominant species mainly include Kobresia humilis, Kobresia pygmaea, Elymus nutans, Festuca rubra, Poa annua, Oxytropis ochrocephala, Gentiana straminea, Potentilla nivea, Saussurea superba, and Thermopsis lanceolata. Coexisting species include Stipa aliena, $P$. annua, K. humilis, Kobresia pygmaea, Oxytropis ochrocephala, Thermopsis lanceolata, S. superba, Leontopodium nanum, G. straminea, $P$. nivea, and Anaphalis lactea Maxim. Stipa aliena and $P$. annua belong to Gramineae, K. humilis and K. pygmaea belong to Cyperaceae, O. ochrocephala and T. lanceolata belong to Leguminous, S. superba, L. nanum, G. straminea, P. nivea, and A. lactea Maxim belong to the Forb group.

\section{Experimental Design}

Three grazing intensities sites are adjacent, and they are enclosed and established in the winter grazing pasture of the same herder. The altitude, climate, and other conditions are the same. Fences separate the plots with different grazing intensities, and the grazing livestock is local Tibetan sheep. Since the 1980s, the three pastures and grazing channel grasslands have carried relatively stable grazing intensity and formed evident grazing gradients in surface characteristics and species composition (Table 1 and Figure 1). 
TABLE 1 | Basic conditions of experimental plots of alpine meadows with different grazing intensities.

\section{Grazing intensity (only sheep ha-1)}

Enclosure (0)

Moderate grazing (7.5)

Heavy grazing (11.3)
Vegetation coverage \%

Approximately 90

$60 \sim 80$

$50 \sim 60$
Dominant species

Elymus nutans, Kobresia humilis, Stipa aliena

Kobresia humilis, Poa annua, Gentiana straminea

Leontopodium nanum, Potentilla nivea, Oxytropis ochrocephala

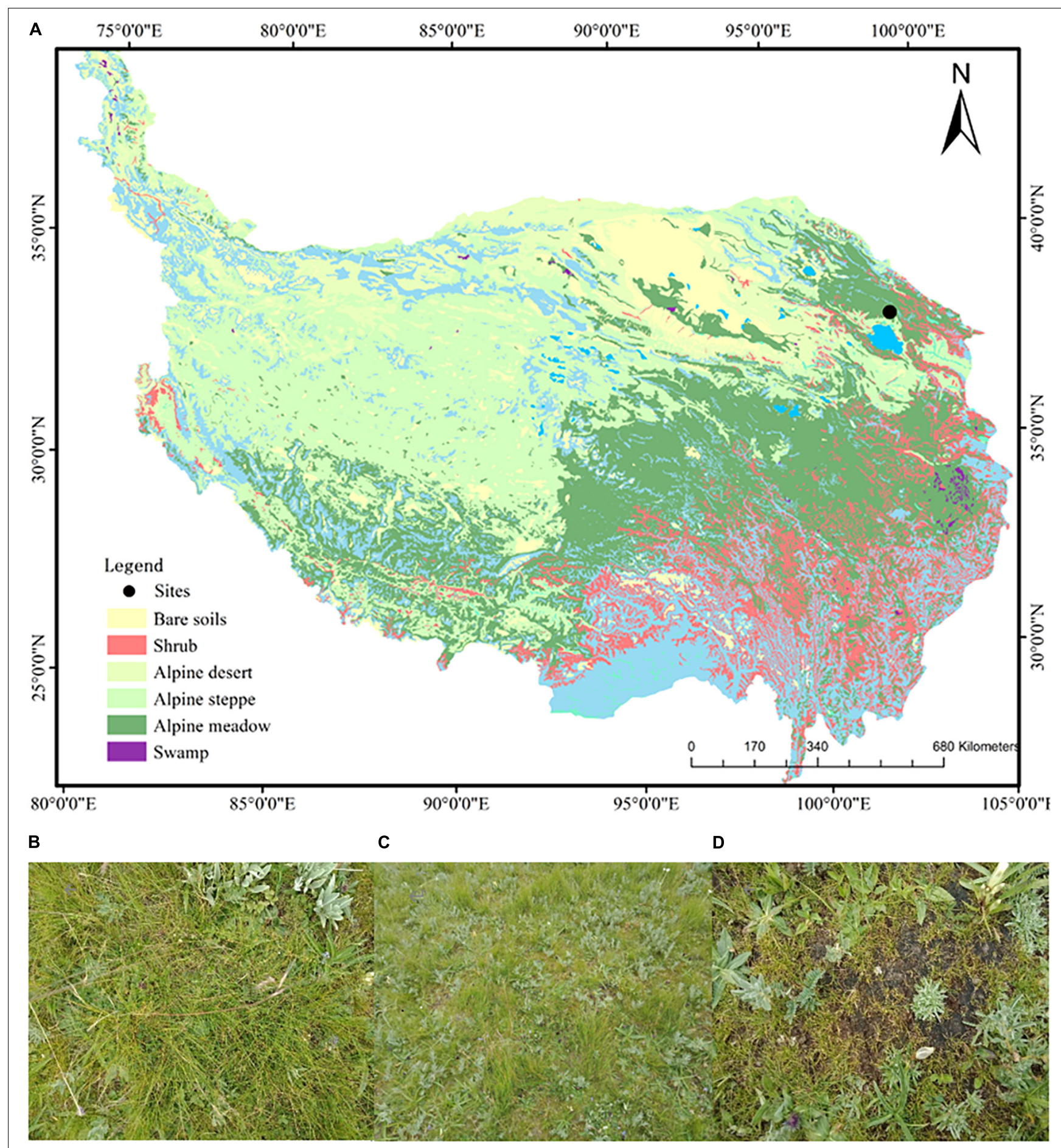

FIGURE 1 | The landscape of three grazing grasslands in Haibei Station [(A) means the main vegetation on the Tibetan Plateau and location of Haibei station and (B-D) indicate the vegetation growth and its main species at 0, 7.5, and 11.3 sheep/ha]. 


\section{Collection of Plant Samples}

The top healthy, complete, and mature leaves (try to pick the same part of each plant) were selected and bagged. Notably, 1520 leaves (at least 10 individual plants growing independently) were collected from each plant. Then, the samples were mixed and packed into cowhide envelopes. Three repeated sampling locations in the same area are $1 \mathrm{~km}$ apart. The standard harvesting method was used to collect plant species at the functional group level $(25 \mathrm{~cm} \times 25 \mathrm{~cm})$. The four functional groups of Gramineae, Cyperaceae, Leguminosae, and Forb are classified and stored in cowhide envelopes.

\section{Collection of Soil Samples}

The root drilling method was used to collect soil samples. Meanwhile, soil samples were collected from the active root zone of $0-20 \mathrm{~cm}$ with three replicates.

The plant leaves were washed with ultrapure water and then dried at $65^{\circ} \mathrm{C}$ to constant weight. The leaves were smashed through a 100 -mesh sieve. Approximately $2 \mathrm{mg}$ of the plant powder sample were burnt in the TOC/TNb analyzer. Furthermore, $\mathrm{CO}_{2}$ was collected and injected into a stable carbon isotope mass spectrometer (Thermo, MAT-253) for the analysis of the stable carbon isotope value. The accuracy of this analysis is $\pm 0.1 \%$.

The expression formula of carbon isotope composition is:

$$
\delta^{13} \mathrm{C}=\left(\mathrm{R}_{\mathrm{sam}} / \mathrm{R}_{\text {sta }}-1\right) \times 1,000
$$

This formula shows the ${ }^{13} \mathrm{C} /{ }^{12} \mathrm{C}$ values of $\mathrm{R}_{\text {sam }}$ and $\mathrm{R}_{\text {sta }}$ of test plants and standard samples, respectively.

\section{Determination of Total Carbon, Soil Organic Carbon, and Total Nitrogen}

Element analyzer (PE 2400 II CHN) is used. Ammonium nitrogen and nitrate nitrogen are measured using a flow analyzer (TRACCS-2000).

\section{Determination of Soil Water Content}

The ring knife method is used. The $0-20 \mathrm{~cm}$ root active soil layer is sampled, weighed in an aluminum box, and dried at $105^{\circ} \mathrm{C}$ to a constant weight, and then the soil water content $\theta_{m}$ is calculated by the following formula:

$$
\theta_{m}=\frac{M_{2}-M_{1}}{M_{1}} \times 100 \%
$$

where $M_{2}$ represents the fresh weight of the soil and $M_{1}$ represents the dry weight of the soil, and the unit is g.

\section{Determination of Soil Bulk Density}

The ring knife method is used. The $0-20 \mathrm{~cm}$ root active soil layer is sampled, weighed in an aluminum box, and dried at $105^{\circ} \mathrm{C}$ to a constant weight, and the soil bulk density is calculated using the following formula:

$$
d_{v}=\frac{M_{2}-M_{1}}{V}
$$

where $M_{2}$ is the total mass of the ring cutter and dry soil weight after drying; $M_{1}$ is the mass of the ring cutter $(\mathrm{g}) ; V$ is the volume of the ring cutter $\left(\mathrm{cm}^{3}\right)$; and $d_{v}$ is the bulk density of the soil and the unit is $\mathrm{g} / \mathrm{cm}^{3}$. Three replicates are set for each plot.

\section{Measurement of Evapotranspiration}

The Lysimeter and electronic balance were used on the sample plot in August 2018. The Lysimeter has a thickness of $2 \mathrm{~cm}$, a diameter of $24 \mathrm{~cm}$, and a height of $22 \mathrm{~cm}$, with a capacity of $8 \mathrm{~L}$. A disk-shaped water container is set below the Lysimeter to measure the leakage. Since the embedded depth of the microLysimeter did not reach the groundwater level, the impact of groundwater was negligible. Since the Haibei station area was flat and the precipitation was small, the surface runoff was insignificant, that is, $\Delta R=0$. According to the observation results, no leakage occurred $(Q=0)$, so the mass change $(\Delta S)$ of Lysimeter is the evapotranspiration. During the setup of three sets of repetitions for each type of plot, the observation time is from 8:00 to 20:00 every day, and the observation is made every $4 \mathrm{~h}$. The calculation method of evapotranspiration is based on the research method of Wu et al. (2013) and others.

$$
\Delta S=P+Q-\Delta R-E
$$

where $\Delta S$ is the change in soil moisture in the Lysimeter; $P$ is the precipitation; $\Delta R$ is the surface runoff; and $E$ is the actual evapotranspiration. The unit of these variables is $\mathrm{mm}$.

\section{Data Analysis}

Mean, standard error, one-way ANOVA, and structural equation model are processed using the $\mathrm{R}$ language software. Among them, the $\delta^{13} \mathrm{C}$ value of grassland plants under different grazing states was used as the test variable to study whether the $\delta^{13} \mathrm{C}$ value of species under the three treatments showed significant differences. The structural equation model is used to study the relationship between the changes in water use efficiency and environmental factors, and environmental factors are estimated through standardized coefficients. To calculate direct and indirect effect coefficient values, the structural equation of water use efficiency includes the following environmental factors: evapotranspiration, total nitrogen, total phosphorus, and soil water content. The comparative coefficient of fit (CFI), the Tucker-Lewis index (TLI), and the root mean square of approximate error (RMSEA) are used for the model evaluation. The maximum likelihood method is the chi-square estimation used by structural equations to evaluate the model chi-square value $\left(\chi^{2}\right)$ and path coefficient. Fitting of the equation is implemented in $\mathrm{R}$ using the lavaan package. All the drawings in the manuscript are completed using the OriginPro 9.1 software.

\section{RESULTS}

\section{Water Use Efficiency Variation Characteristics of Dominant Species at Different Grazing Intensities}

Moderate and heavy grazing increased the $\delta^{13} \mathrm{C}$ value of the dominant species by $5.25 \%$ and $1.48 \%$, respectively. The $\delta^{13} \mathrm{C}$ value of each species differed significantly in both the enclosure 
TABLE 2 | The $\delta^{13} \mathrm{C}$ value of dominant species in different grazing intensities.

\begin{tabular}{llcl}
\hline Grazing intensity & Dominant species & $\delta^{\mathbf{1 3}} \mathbf{C}(\mathbf{\%})$ & $\begin{array}{c}\text { Mean value } \\
\text { of } \delta^{\mathbf{1 3}} \mathbf{C ~}(\mathbf{\%})\end{array}$ \\
\hline Enclosure & Elymus nutans & $-27.41 \pm 0.09$ & $-27.61 \pm 0.59 \mathrm{a}$ \\
& Kobresia humilis & $-28.71 \pm 0.06$ & \\
& Stipa aliena & $-26.70 \pm 0.10$ & \\
Moderate grazing & Kobresia humilis & $-25.98 \pm 0.09$ & $-26.16 \pm 0.18 \mathrm{a}$ \\
& Kobresia pygmaea & $-27.58 \pm 0.14$ & \\
Heavy grazing & Gentiana straminea & $-24.92 \pm 0.07$ & \\
& Leontopodium nanum & $-28.08 \pm 0.01$ & $-27.20 \pm 0.44 a$ \\
& Potentilla nivea & $-26.88 \pm 0.04$ & \\
& Oxytropis ochrocephala & $-26.66 \pm 0.03$ & \\
& &
\end{tabular}

The above table shows the mean \pm standard error. The same letter in the same column under the same treatment indicates that the difference between the two is not significant, and different letters indicate significant difference $(P<0.05)$.

plots and grazing treatments. The average $\delta^{13} \mathrm{C}$ values of the dominant species in the three grazing treatments, enclosure, moderate grazing, and heavy grazing gradients were -27.61 , -26.16 , and $-27.20 \%$, respectively. The $\delta^{13} \mathrm{C}$ value of the dominant species first increased and then decreased with the increasing grazing intensity. The overall range of the nine species was from $-24.92 \pm 0.07$ to $-28.08 \pm 0.01 \%$. The former value is $3.16 \%$ higher than the latter, with an approximately $12.68 \%$ reduction. G. straminea and $L$. nanum had the highest and lowest values, respectively. The $\delta^{13} \mathrm{C}$ values of Stipa aliena, G. straminea, and $O$. ochrocephala were the highest under enclosure, moderate grazing, and heavy grazing gradients (Table 2). Particularly, our results suggest that both grazing activities improved the WUE of the dominant species in alpine meadows.

\section{Water Use Efficiency Variation Characteristics of 11 Coexisting Species at Different Grazing Intensities}

The average $\delta^{13} \mathrm{C}$ value of functional group plants under moderate grazing was the largest, and their average $\delta^{13} \mathrm{C}$ values in the three experimental treatments, namely, enclosure, moderate grazing, and heavy grazing gradients, were $-27.09,-27.00$, and $-27.04 \%$, respectively. The $\delta^{13} \mathrm{C}$ values of $G$. straminea and A. lactea Maxim were the highest and lowest, respectively. The $\delta^{13} \mathrm{C}$ values of $P$. annua, K. humilis, $K$. pygmaea, and $P$. nivea increased significantly under moderate grazing $(P<0.05$, Figure 2). L. nanum, O. ochrocephala, and A. lactea Maxim had the highest $\delta^{13} \mathrm{C}$ values under heavy grazing. Stipa aliena, T. lanceolata, S. superba, and $G$. straminea had the highest $\delta^{13} \mathrm{C}$ values in the enclosure. In other words, moderate grazing can increase the coexisting species plant WUE by $3.32 \%$ compared with that of the enclosure.

\section{Variation Characteristics of Functional Group Water Use Efficiency in Different Grazing Intensity}

The $\delta^{13} \mathrm{C}$ values of the two functional groups of Gramineae and Cyperaceae were high under moderate grazing. Both Gramineae and Cyperaceae were regarded as good forages.

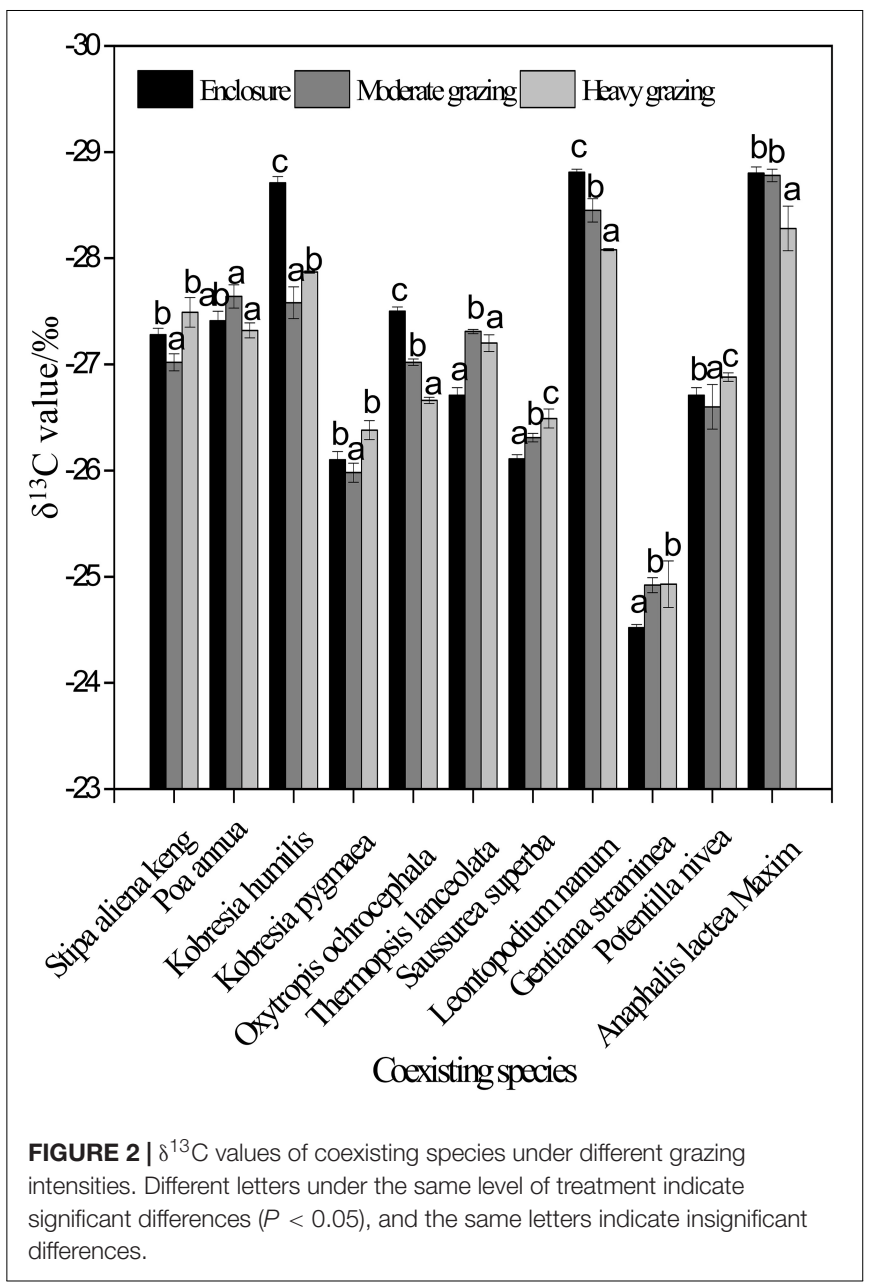

Moderately grazing increases forage WUE. The $\delta^{13} \mathrm{C}$ values of the two functional groups of Leguminosae and Forb were the highest under heavy grazing. Drought tolerance increased with the increasing grazing intensity. Except for Gramineae plants, the WUE of the other three functional groups, namely, Cyperaceae, Leguminosae, and Forb, did not show any significant difference under the three treatments. The WUE of Gramineae plants was more sensitive and adaptive. Moderate grazing significantly increased Gramineae plant $\delta^{13} \mathrm{C}$ and WUE by approximately $4.84 \%$ compared with that of the control $(P<0.05$, Figure 3$)$. The $\delta^{13} \mathrm{C}$ values of Gramineae and Cyperaceae plants first increased and then decreased with grazing intensity, whereas Leguminosae and Forb showed an upward trend.

Overall grazing activity increased the $\delta^{13} \mathrm{C}$ value of the plants. The average $\delta^{13} \mathrm{C}$ values of each functional group in the three treatments of the enclosure, moderate grazing, and heavy grazing were -27.47, -26.90, and $-26.97 \%$, respectively. Moderate and heavy grazing increased WUE by $2.07 \%$ and $1.82 \%$, respectively, compared with the enclosure. 


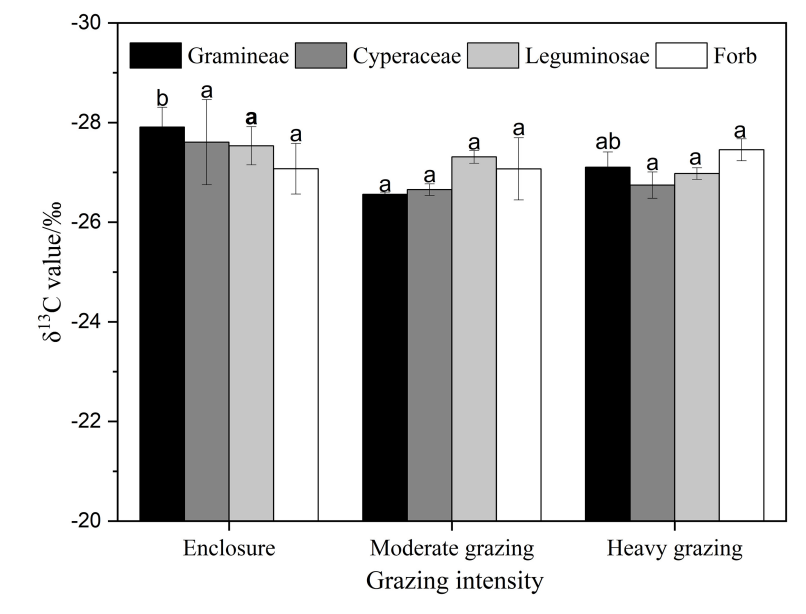

FIGURE $3 \mid \delta^{13} \mathrm{C}$ values of functional group species under different grazing intensities. Different letters of the bar graph of the same color indicate a significant difference between the two, and the same letter indicates that the difference is not significant.

\section{Effect of Soil Physical and Chemical Properties Due to Water Use Efficiency Variation}

Soil evapotranspiration, soil organic carbon, water content, and soil bulk density were negatively correlated with the $\delta^{13} \mathrm{C}$ value; however, only evapotranspiration and soil organic carbon were significantly correlated $(P<0.05)$. In contrast, available nitrogen as well as grazing intensity was positively correlated with WUE $(P<0.01$, Table 3). Notably, grassland WUE was higher in tolerant environments.

\section{Structural Equation Model of the Influence of Environmental Factors on Water Use Efficiency in Alpine Meadows}

The structural equation model results indicated that evapotranspiration had a direct and significant negative correlation effect on the $\delta^{13} \mathrm{C}$ value $(P<0.05)$. Furthermore, available nitrogen, soil organic carbon, soil bulk density, and soil water content indirectly affected the $\delta^{13} \mathrm{C}$ value (Figure 4). Meanwhile, the indirect effects of soil available nitrogen,

TABLE 3 | Response of $\delta^{13} \mathrm{C}$ value of alpine meadow to climate and soil physical and chemical properties.

\begin{tabular}{lccc}
\hline Moderators & Simulated equation & $\boldsymbol{P}$ & $\boldsymbol{R}^{\mathbf{2}}$ (\%) \\
\hline Evapotranspiration & $Y=-0.06 \mathrm{X}-22.24$ & $<0.05$ & 62.60 \\
Soil organic carbon & $Y=-0.43 X-24.05$ & $<0.05$ & 57.10 \\
Grazing intensity & $Y=0.22 X-27.31$ & 0.07 & 53.80 \\
Available nitrogen & $Y=0.08 X-24.78$ & $<0.01$ & 49.20 \\
Soil water content & $Y=-0.12 X-26.23$ & 0.14 & 25.10 \\
Soil bulk density & $Y=-0.42 X-26.77$ & 0.38 & 15.00 \\
\hline
\end{tabular}

$Y$ represents the community level $\delta^{13} \mathrm{C}$ value.

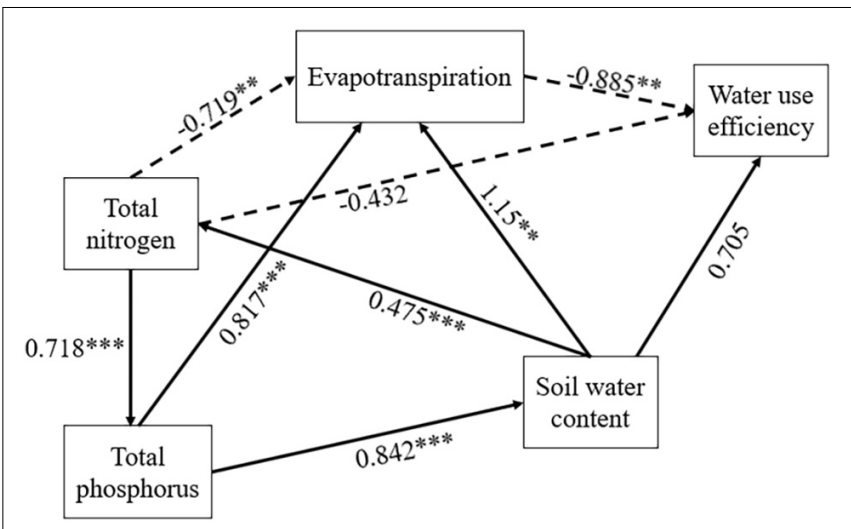

FIGURE 4 | Structural equation model diagram of the influence of environmental factors on plant water use efficiency. The solid line and the dashed line represent the positive and negative correlations, respectively, and the value on the arrow is the standard path coefficient. Data whose absolute value is $<0.1$ are not shown in the figure. ${ }^{* *}$ indicates $P<0.01$ and ***indicates $P<0.001$.

evapotranspiration, and soil bulk density were higher, with soil organic carbon from -0.85 to 0.51 . The soil organic carbon and available nitrogen showed a positive effect by evapotranspiration of approximately 0.27 and 0.22 , respectively. Evapotranspiration and available nitrogen showed a positive and negative effect of approximately 0.22 and -0.15 of soil water content, respectively. Furthermore, available nitrogen showed a positive effect on WUE with a soil water content of 0.38 .

\section{DISCUSSION}

\section{The Response and Adaptation of Water Use Efficiency of Alpine Meadow Ecosystem to Grassland Grazing Activities}

Previous studies have shown that grazing activities reduce the WUE of plant species (An and Li, 2015; Zhu et al., 2016; Huang and Luo, 2017; Wang et al., 2017). However, our experimental results show that for all the dominant, coexisting, and functional group species, the WUE of plants was the highest under moderate grazing treatment, and grazing activities increased the WUE of plants. Similar results by Cavalcante et al. (2016) revealed that moderate grazing increased WUE by $37.72 \%$ compared to traditional grazing. In Inner Mongolia, the typical grassland community WUE was highest under moderate grazing (Lv, 2016), which was increased by $62.86 \%$ compared to no grazing. Grassland WUE increased by $0.56 \%$ under moderate grazing in Inner Mongolia S. breviflora (Wang, 2018).

Grazing plays an essential role in balancing plant ecosystems (Zhu et al., 2016). Moderate grazing improved grassland biomass and richness, but heavy grazing significantly decreased it (Du et al., 2019). In this study, the WUE of plants was the highest under moderate grazing. This indicates that the plants were highly tolerant to drought-prone environments under 
moderate grazing conditions. The increase in WUE under moderate grazing may be due to the following two reasons, namely, (1) livestock foraging on plants damages the leaves under moderate grazing and the canopy structure of plants changes and (2) moderate grazing treatment can improve the utilization rate of grassland resources (Zhu et al., 2020), is conducive to grassland health and the maintenance of grassland productivity (Shi et al., 2019), and promotes the species diversity of plant communities (Liu et al., 2014). Therefore, WUE is the highest under moderate grazing to reduce the redundancy of grassland communities (Dong et al., 2004) and increase the grazing tolerance of grassland plants (Lv, 2016; Wang, 2018). In addition, grazing can increase soil fertility through livestock manure and urine, improve the microenvironment for plant growth, and enhance viability. After grazing, the resource utilization capacity of plants increases, thereby increasing their WUE (Zhang et al., 2020). Moreover, studies have shown that the saliva remaining on the section of the gnawed plant can promote plant growth, thereby increasing the WUE of the plant (Johnston and Bailey, 2008).

Water use efficiency showed a downward trend under heavy grazing compared to moderate grazing. During water stress, WUE can be improved to ensure water supply (Sun et al., 2005). This may be because if the grassland degradation is very high, it results in biomass reduction (Du et al., 2019). As the vegetation is scarce under severe grazing conditions, the bare grassland area was found to be more significant. Plant WUE showed a downward trend. However, the WUE of Forb was the highest under heavy grazing. Due to the large amount of grazing by livestock, the growth space of Forb increased, which led to the dominant position of Forb in the sample plot. Therefore, Forb has the highest WUE and adaptability to the environment at the functional group level. Gramineae, which livestock are fond of, had the lowest WUE.

\section{Adaptation of Water Use Efficiency of Alpine Meadow Ecosystem to Environmental Factors}

Environmental factors that affect the process of gas exchange metabolism also affect the WUE, soil water content (Ehleringer, 1994; Stewart et al., 1995; Korol et al., 1999; Wu et al., 2019), precipitation (Stewart et al., 1995; Anderson et al., 2000), evapotranspiration (Xu et al., 1998), and nitrogen availability of many plants (Hogberg et al., 1993; Guehl et al., 1995). Soil water content, precipitation, and evapotranspiration were negatively correlated with WUE, which is consistent with the results of this experiment. This is also because when the water content decreases, plants adapt better to the environment by increasing their own WUE (Chen, 2003; Sun et al., 2005). The studies have shown that evapotranspiration decreases with grazing intensity (Shu et al., 2019). The increase in WUE is related to lower evapotranspiration, community coverage, and biomass of dominant species. The greater the plant evapotranspiration, the lower water content the plant can utilize. Our findings are therefore consistent with those of several other studies
(Varnamkhasti et al., 1995; Xu et al., 1998; Cavalcante et al., 2016). There was a negative correlation between WUE and soil bulk density. It has been established that soil water content shows a downward trend (Shu et al., 2019). This could be because when plants are subjected to water stress, they increase their WUE to survive better. Furthermore, there was a negative correlation between WUE and soil organic carbon content, which may be due to the increased soil organic matter content in the enclosure. Microorganisms preferentially use ${ }^{12} \mathrm{C}$ to enrich the residual organic matter with ${ }^{13} \mathrm{C}$ in soil organic carbon decomposition. Because the enclosure slows down this decomposition process, the WUE in the enclosed plot was lower than that in the free grazing plot (Zhu et al., 2020). Nitrogen plays a vital role in the growth and development of plants, and an increase in soil nitrogen content can improve plant WUE, ensuring the sustainable development of grasslands (Chen, 2003).

\section{CONCLUSION}

The present study investigated the WUE of plants at the level of dominant species, coexisting species, and functional groups of alpine meadows under the three treatments, namely, in an enclosure, moderate grazing, and heavy grazing, in Haibei, Qinghai. Furthermore, we examined the adaptation mechanism of WUE in the alpine meadows under different grazing intensities. The following conclusions were drawn:

i) Based on the analysis from the perspective of functional groups, the order of WUE is Gramineae $>$ Cyperaceae $>$ Forb $>$ Leguminous.

ii) The WUE of the dominant species, coexisting species, and functional group level species was the highest under moderate grazing, followed by heavy grazing, and the lowest in an enclosure.

iii) Grazing activities increased the WUE of plants.

iv) There was a negative correlation between soil water content, evapotranspiration, soil bulk density, soil organic carbon, and WUE. Interestingly, further analysis showed that evapotranspiration is the main driving factor in the WUE of alpine meadows at high altitudes in Qinghai.

The WUE of plants in alpine meadow ecosystems under grazing can also reflect the health of grassland ecosystems to a certain extent. Higher plant WUE means that grasslands have high adaptive strategies. Appropriate grazing treatment is more conducive to the development of meadow animal husbandry and the health of the grassland environment. Therefore, our experiment provides new insights that grazing can moderately increase the WUE of palatability forages to a certain extent, and the drought tolerances of Leguminosae and Forb increased with increasing grazing intensity.

\section{DATA AVAILABILITY STATEMENT}

The raw data supporting the conclusions of this article will be made available by the authors, without undue reservation. 


\section{AUTHOR CONTRIBUTIONS}

YW: formal analysis (lead). WP: data curation (lead). GC: data curation (supporting). XG: investigation (supporting). HZ: software (supporting). YD: writing-review and editing (supporting). All authors contributed to the article and approved the submitted version.

\section{REFERENCES}

An, H., and Li, G. Q. (2015). Effects of grazing on carbon and nitrogen in plants and soils in a semiarid desert grassland. China. J. Arid Land. 7, 341-349. doi: 10.1007/s40333-014-0049-x

Anderson, J. E., Kriedemann, P. E., and Austin, M. P. (2000). Eucalypts forming a canopy functional type in dry sclerophyll forests respond differentially to environment. Aust. J. Bot. 48, 759-775. doi: 10.1071/BT99073

Cao, G. M., Lin, L., Zhang, F. W., Li, Y. K., Du, Y. G., Guo, X. W., et al. (2018). Longterm ecological research and experimental demonstration provide theoretical and technical support for the adaptive management of alpine grassland. J. Chin. Acad. Sci. 33, 1115-1126. doi: 10.16418/j.issn.1000-3045.2018.10.013

Cavalcante, A. C. R., Santos, P. M., Júnior, J. A. A. C., Cândido, M. J. D., and Lemos, N. L. S. (2016). Efficiency of water use and nitrogen for goat milk production in irrigated pasture to different management. Arq. Bras. Med. Vet. Zootec. 68, 1374-1380. doi: 10.1590/1678-4162-8682

Chen, S. P. (2003). Research on the Main Plant Species, Functional Groups and Community Water use Efficiency of the Xilin River Basin in Inner Mongolia. Beijing: Graduate University of the Chinese Academy of Sciences.

Dong, S. K., Ding, L. M., Xu, M. Y., Long, R. J., and Hu, Z. Z. (2004). Effects of grazing intensity on leaf characteristics and forage productivity on mixed perennial grasses in alpine region of Tibetan Plateau. Sci. Agric. Sin. 37, 136-142.

Du, Y. G., Ke, X., Guo, X. W., Cao, G. M., and Zhou, H. K. (2019). Soil and plant community characteristics under long-term continuous grazing of different intensities in an alpine meadow on the Tibetan plateau. Biochem. Syst. Ecol. 85, 72-75. doi: 10.1016/j.bse.2019.05.012

Ehleringer, J. R. (1994). "Variation in gas exchange characteristics among desert plants," in Ecophysiology of Photosynthesis, eds E.-D. Schulze and M. M. Caldwell (New York, NY: Springer-Verlag), 361-387. doi: 10.1007/978-3-64279354-7_18

Farquhar, G. D., O'Leary, M. H., and Berry, J. A. (1982). On the relationship between carbon isotope discrimination and the intercellular carbon dioxide concentration in leaves. Funct. Plant Biol. 9, 281-292. doi: 10.1071/PP9820121

Guehl, J. M., Fort, C., and Ferhi, A. (1995). Differential response of leaf conductance, carbon isotope discrimination and water-use efficiency to nitrogen deficiency in maritime pine and pedunculate oak plants. New Phytol. 131, 149-157. doi: 10.1111/j.1469-8137.1995.tb05716.x

He, H. D., Yang, Y. S., Zhu, J. B., Li, H. Q., Wei, Y. X., and Li, Y. N. (2017). Effects of seasonal grazing on vegetation water consumption and water utilization efficiency in alpine meadow of the source regions of the Yellow River. J. Glaciol. Geocryol. 39, 130-139. doi: 10.7522/j.issn.1000-0240.2017.0016

Hogberg, P., Johannisson, C., and Hallgern, J. E. (1993). Studies of ${ }^{13} \mathrm{C}$ in the foliage reveal interactions between nutrients and water in forest fertilization experiments. Plant Soil 152, 207-214. doi: 10.1007/BF00029090

Huang, X. T., and Luo, G. P. (2017). Spatio-temporal characteristics of evapotranspiration and water use efficiency in grasslands of Xinjiang. Chin. J. Plant Ecol. 41, 506-518. doi: 10.17521/cjpe.2016.0142

Jiang, S. Z., Liang, C., Cui, N. B., Zhao, L., Liu, C. W., Feng, Y., et al. (2020). Water use efficiency and its drivers in four typical agroecosystems based on flux tower measurements. Agric. For. Meteorol. 295:108200. doi: 10.1016/j.agrformet.2020. 108200

Johnston, C. T., and Bailey, D. G. (2008). "FPGA implementation of a single pass connected components algorithm," in Proceedings of the IEEE International Symposium on Electronic Design. (New Jersey, NJ: IEEE), doi: 10.1109/DELTA. 2008.21

Korol, R. L., Kirschbaum, M. U. F., Farquhar, G. D., and Jeffreys, M. (1999). Effects of water status and soil fertility on the $\mathrm{C}$-isotope signature in Pinus radiata. Tree Physiol. 19, 551-562. doi: 10.1093/treephys/19.9.551

\section{FUNDING}

This work was supported by the Qinghai Innovation Platform Construction Project (2020-KF-12), Western Light of Chinese Academy of Sciences for Talents, and National Natural Science Foundation of China (31770532).

Lin, B., Zhao, X. R., Zheng, Y., Qi, S., and Liu, X. Z. (2017). Effect of grazing intensity on protozoan community, microbial biomass, and enzyme activity in an alpine meadow on the Tibetan Plateau. J. Soils Sediments 17, 2752-2762. doi: $10.1007 / \mathrm{s} 11368-017-1695-3$

Lin, X. W., Zhang, Z. H., Wang, S. P., Hu, Y. G., Xu, G. P., Luo, C. Y., et al. (2011). Response of ecosystem respiration to warming and grazing during the growing seasons in the alpine meadow on the Tibetan plateau. Agric. For. Meteorol. 151, 792-802. doi: 10.1016/j.agrformet.2011.01.009

Liu, X. N., Li, G., Zhao, X., Zhang, B. B., Liu, B. R., Dong, K. H., et al. (2014). The effects of grazing on the biomass and plant diversity of Leymus chinensis community. Acta Agrestia Sin. 22, 942-948.

Liu, Y. J., Xu, N., and Niu, H. S. (2016). Response patterns of foliar $\delta^{13} \mathrm{C}$ and $\delta^{15} \mathrm{~N}$ to environmental factors for the dominant plants in Inner Mongolia steppe. China. J. Ecol. 36, 235-243. doi: 10.5846/stxb201405261081

Lv, W. W. (2016). The Effects of Grazing on Water Use Efficiency of Dominant Plants in Typical Steppe. Hohhot: Inner Mongolia University.

Shen, F. F., Fan, H. B., Wu, J. P., Liu, W. F., and Lei, X. C. (2017). Review on carbon isotope composition $\left(\delta^{13} \mathrm{C}\right)$ and its relationship with water use efficiency at leaf level. J. Beijing For. Univ. 39, 114-124. doi: 10.13332/j.1000-1522.20170142

Shen, H., Dong, S. K., Li, S., Xiao, J. N., and Yeomans, G. C. (2019). Grazing enhances plant photosynthetic capacity by altering soil nitrogen in alpine grasslands on the Qinghai-Tibetan plateau. Agric. Ecosyst. Environ. 280, 161168. doi: 10.1016/j.agee.2019.04.029

Shi, X. L., Wu, M. Y., and Zhang, N. (2020). Characteristics of water use efficiency of typical terrestrial ecosystems in China and its response to climate factors. Trans. Chin. Soc. Agric. Eng. 36, 152-159. doi: 10.11975/j.issn.1002-6819.2020. 09.017

Shi, Y., Hu, Y. H., Gao, H. J., Luo, Q. Y., and Yu, Y. W. (2019). The community vegetation composition and stability characteristics of alpine meadow under two grazing modes. Acta Pratacult. Sin. 28, 1-10.

Shu, K., Ke, X., Xin, Y., Guo, X. W., Cao, G. M., and Du, Y. G. (2019). Comparative study on evapotranspiration characteristics of Multi-stable alpine meadow ecosystem on the Tibetan Plateau. Grassl. Turf 39, 83-88. doi: 10.13817/j.cnki. cyycp.2019.06.012

Stewart, G. R., Turnbull, M. H., Schmidt, S., and Erskine, P. D. (1995). ${ }^{13}$ C natural abundance in plant communities along a rainfall gradient: a biological integrator of water availability. Aust. J. Plant Physiol. 22, 51-55. doi: 10.1071/ pp9950051

Su, P. X., Yan, Q. D., and Chen, H. S. (2005). $\delta^{13} \mathrm{C}$ values and water use efficiency of the leaves and assimilating shoots of desert plants. Acta Bot. Boreali Occidentalia Sin. 25, 727-732.

Sun, S. F., Hang, J. H., Lin, G. H., Zhao, W., and Han, X. G. (2005). Application of stable isotope technique in the study of plant water use. Acta Oecol. 25, 2362-2371.

Varnamkhasti, A. S., Milchunas, D. G., and Goetz, W. K. L. (1995). Production and rain use efficiency in short-grass steppe: grazing history, defoliation and water resource. J. Veg. Sci. 6, 787-796. doi: 10.2307/3236392

Wang, M. L., Lai, J. P., Hu, K. T., and Zhang, D. L. (2016). Compositions of stable organic carbon and nitrogen isotopes in wetland soil of Poyang Lake and its environmental implications. China Environ. Sci. 36, 500-505.

Wang, Y. T. (2018). Effect of Stocking Rate on Carbon Isotope in the Main Species of Stipa breviflora Steppe. Mongolia: Mongolian University.

Wang, Y. T., Wang, X., Zhao, T. Q., Jia, L. X., Yang, Y., Qiao, J. R., et al. (2017). Integration of water and nitrogen use efficiency of plant function groups in the Stipa breviflora grassland of inner Mongolia along grazing gradients. Ecol. Environ. Sci. 26, 964-970.

Wu, J. S., Zhang, X. Z., Shen, Z. X., Shi, P. L., Xu, X. L., and Li, X. J. (2013). GrazingExclusion Effects on Aboveground Biomass and Water-Use Efficiency of Alpine 
Grasslands on the Northern Tibetan Plateau. Rangel. Ecol. Manag. 66, 454-461. doi: 10.2111/REM-D-12-00051.1

Wu, X. C., Li, X. Y., Chen, Y. H., Bai, Y., Tong, Y. Q., Wang, P., et al. (2019). Atmospheric water demand dominates daily variations in water use efficiency in alpine meadows, Northeastern Tibetan Plateau. J. Geophys. Res. 124, 2174-2185. doi: 10.1029/2018JG004873

Xu, M. H., Peng, F., You, Q. G., Guo, J., Tian, X. F., Xue, X., et al. (2015). Year-round warming and autumnal clipping lead to downward transport of root biomass, carbon and total nitrogen in soil of an alpine meadow. Environ. Exp. Bot. 109, 54-62. doi: 10.1016/j.envexpbot.2014. 07.012

Xu, R., Niu, H. S., and Song, B. Y. (1998). Water use countermeasures of Leymus chinensis and its population growth potential based on water balance. Acta Agrestia Sin. 6, 265-274.

Zhang, C. J., Chen, F. H., and Jin, M. (2003). Study on modern plant C13 in western China and its significance. Chin. J. Geochem. 22, 97-106. doi: 10.1007/ BF02831518

Zhang, T., Xu, M. J., Zhang, Y. J., Zhao, T. H., An, T. T., Li, Y. G., et al. (2019). Grazing-induced increases in soil moisture maintain higher productivity during droughts in alpine meadows on the Tibetan Plateau. Agricul. Forest Meteorol. 269-270, 249-256. doi: 10.1016/j.agrformet.2019.02.022

Zhang, Y. J., Zhu, J. T., Shen, R. N., and Wang, L. (2020). Research progress on the effects of grazing on grassland ecosystem. Chin. J. Plant Ecol. 44, 553-564. doi: $10.17521 /$ cjpe.2019.0314
Zhu, G. D., Guo, N., Lu, G. Y., and Wang, C. J. (2020). The effect of enclosure on soil physical and chemical properties and stable carbon and nitrogen isotopes in Inner Mongolia desert steppe. Soil 52, 840-845. doi: 10.13758/j.cnki.tr.2020. 04.026

Zhu, J. T., Zhang, Y. J., and Liu, Y. J. (2016). Effects of short-term grazing exclusion on plant phenology and reproductive succession in a Tibetan alpine meadow. Sci. Rep. 6:27781. doi: 10.1038/srep27781

Conflict of Interest: The authors declare that the research was conducted in the absence of any commercial or financial relationships that could be construed as a potential conflict of interest.

Publisher's Note: All claims expressed in this article are solely those of the authors and do not necessarily represent those of their affiliated organizations, or those of the publisher, the editors and the reviewers. Any product that may be evaluated in this article, or claim that may be made by its manufacturer, is not guaranteed or endorsed by the publisher.

Copyright $(2021$ Wang, Pei, Cao, Guo, Zhou and Du. This is an open-access article distributed under the terms of the Creative Commons Attribution License (CC BY). The use, distribution or reproduction in other forums is permitted, provided the original author(s) and the copyright owner(s) are credited and that the original publication in this journal is cited, in accordance with accepted academic practice. No use, distribution or reproduction is permitted which does not comply with these terms. 